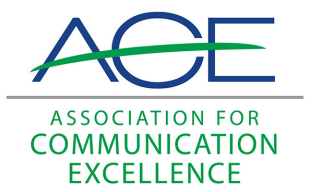

Journal of Applied Communications

\title{
Food, Food Stamps and Nutrition: An Evaluation of Methods of Recruitment and Instruction ; Public Communications Campaigns; Cartoons: When are they Effective; Science Meets the Press; Multimedia Instruction: High Learning, Low Cost
}

Debrah H. Jefferson

James W. King

Dot Sparer

Follow this and additional works at: https://newprairiepress.org/jac (c) (i)(2)

This work is licensed under a Creative Commons Attribution-Noncommercial-Share Alike 4.0 License.

\section{Recommended Citation}

Jefferson, Debrah H.; King, James W.; and Sparer, Dot (1982) "Food, Food Stamps and Nutrition: An Evaluation of Methods of Recruitment and Instruction ; Public Communications Campaigns; Cartoons: When are they Effective; Science Meets the Press; Multimedia Instruction: High Learning, Low Cost," Journal of Applied Communications: Vol. 65: Iss. 2. https://doi.org/10.4148/1051-0834.1748

This Review is brought to you for free and open access by New Prairie Press. It has been accepted for inclusion in Journal of Applied Communications by an authorized administrator of New Prairie Press. For more information, please contact cads@k-state.edu. 
Food, Food Stamps and Nutrition: An Evaluation of Methods of Recruitment and Instruction ; Public Communications Campaigns; Cartoons: When are they Effective; Science Meets the Press; Multimedia Instruction: High Learning, Low Cost

\author{
Abstract \\ Reviews of "Food, Food Stamps and Nutrition: An Evaluation of Methods of Recruitment and Instruction," \\ by Richard A. Krueger and Bethaviva Cohen; Public Communication Campaigns, edited by Ronald E. Rice \\ and William J. Paisley; "Cartoons: When are they Effective," by James M. Nehiley, James Stephens, and \\ John Sutherland; "Science Meets the Press," by William E. Burrows; "Multimedia Instruction: High \\ Learning, Low Cost," by Karin Kristiansson.
}




\section{Reviews}

"Food, Food Stamps and Nutrition: An Evaluation of Methods of Recruitment and Instruction." Richard A. Krueger and Bethaviva Cohen. Sociology of Rural Life, Edited by P.J. Tichenor (Agricultural Extension Service and Agricultural Experiment Station, Institute of Agriculture, Forestry, and Home Economics, University of Minnesota-St. Paul, Vol. 4, No. 2, Summer, 1981), pages 4-6.

Since its inception, EFNEP has faced obstacles in reaching target clientele. Traditionally, one-to-one, or personal, contact has been used. Most states recognize the enormous time and limited number of contacts who can be reached this way. Alternative delivery systems to reach clientele homemakers were needed to make the program more cost effective, while maintaining quality nutrition education.

During 1980, nine Minnesota counties participated in a pilot project funded by USDA. The target EFNEP audience came from the USDA food stamp program. The KruegerCohen article reported on the effectiveness of recruitment and delivery methods to reach this potential audience.

The basic research methods involved three test sites with different approaches to instruction and recruitment. The first site established recruitment booths at the food stamp offices. Monthly promotional displays were staffed by EFNEP assistants who provided food stamp recipients with on-site food and nutrition demonstrations. Prospective clientele could request more information after this initial contact. Follow-up surveys of food stamp recipients and EFNEP assistants, plus interviews and observations were conducted. 


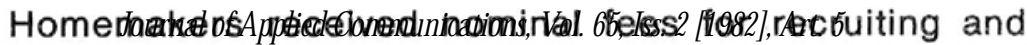
teaching new homemakers at the second site. These paid homemaker-recruiters had successfully participated in the EFNEP program. They were referred to as helpers.

The helpers spent six months recruiting and teaching, they spent a second six-month period just recruiting. The effectiveness of helper teaching was measured against the 24Hour Food Recall to measure dietary adequacy within the Basic Food Food Groups.

Site three used inter-agency promotion plus a correspondence course. This system hinged upon correspondence lessons and telephone visits.

The Krueger-Cohen study compared these approaches:

(1) traditional recruiting with one-to-one home visits;

(2) modified recruiting with traditional one-to-one visits; and

(3) modified recruiting with correspondence lessons and telephone visits.

All the methods used the diet recalls, program assistants, and supervising home economists. Just the method of approach varied. Conclusions based upon the approach at site one indicated demonstrations at food stamp distribution points showed promise because new homemakers were encouraged to enroll. But the approaches' efforts to form homemaker groups proved unsuccessful.

Assessment of site two showed helpers were not as effective as program assistants in providing nutrition education based upon diet recalls. The helpers, however, were able to provide some instructions at a lower cost than the assistants. The helpers also preferred recruiting with instruction over just recruiting because it also increased their self-esteem.

When the first two methods were compared with the third site method, the latter showed the greatest promise. Case loads of assistants using site three's approach increased 92 percent over loads during the previous year. Case loads for site two increased 82 percent and those in site one increased 60 percent.

Researchers concluded the large increase in case loads for approach three was partly due to the assistants' ability to maintain contact with the homemakers. Regular instructional contact was deemed mandatory to assure adequate nutritional progress. Correspondence lessons and telephone visits were the most cost effective way to manage large case loads and maintain quality instruction. 


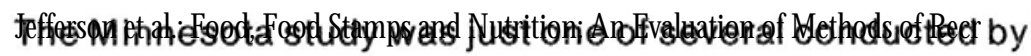
states through a grant from USDA. Over the next year, more states will participate in pilot-study tests for recruitment and instruction. Their results should affect future EFNEP instructional efforts.

Debrah H. Jefferson University of Missouri-Columbia

\section{Public Communication Campaigns. Ronald E. Rice and William J. Paisley, editors. Beverly Hills: Sage Publications, 1981.}

The 14 original articles assembled in Rice and Paisley's book present a background for planning, implementing and evaluating public communication campaigns. From historical campaigns to reviews of current efforts and from the theoretical aspects to the practical realities, the material is current, relevant and readable. Three major areas are summarized and highlighted: communication process theories, communication strategies, and public communication evaluation, both formative and summative aspects.

The first section of the book presents the historical and theoretical foundations of campaigns. Of particular interest is McGuire's chapter with his communication/persuasion model. McGuire's model is noteworthy because it suggests a practical planning scheme based on input and output variables. Input variables include the source, the message, the channel, the receiver and change factors. Output variables describe 12 potential audience behaviors relevant to the message, ranging from selective exposure to the integration of the behavior in the personality.

"Campaign Experiences from the Field" builds on the communication process theories of the first section and presents a variety of campaigns-antismoking, heart disease prevention, family planning, wildfire prevention, energy utilization, political efforts, and communication programs in the People's Republic of China. Examples of communication planning, message design, and mass and interpersonal communication give the reader a unique aspect of the book. The authors also summarize previous campaign studies and detail their transferable aspects.

For example, in the article on China, Liu discusses the structure of a typical campaign, reviewing five design components. Then he examines the Chinese experience and 


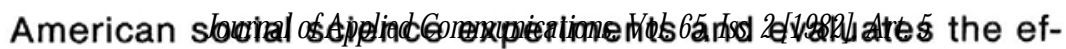
fectiveness of the Chinese campaigns. Finally, lessons derived from the Chinese experiences are presented for communication planners.

The third section is a compilation of articles entitled "Putting Theory into Practice." Issues discussed in the four chapters are formative and summative evaluation, campaign effectiveness and social marketing. Specific advice and guidelines are offered in each chapter.

Perhaps the book's greatest strength is that all these articles have been assembled to address the development of public communication campaigns. The information flows in a logical manner and covers the entire spectrum of campaign components. A comprehensive bibliography has been included so a reader can scan for articles and research specific to his own particular needs.

Public Communication Campaigns fills a need. It presents lessons from past campaigns that until now have only been randomly reported. The authors analyze and synthesize these reports into suggestions which emerge from each of the 14 articles. Perspectives for planning, implementing and evaluating campaigns can be found throughout the collection.

The book also is an important one. It presents communication theories in the light of reality. It offers a welcome blend of theory and reality, emphasizing the primary need to examine audiences and then design specific messages that will relate to them.

Such a work makes one request a companion volume; one in which the case studies and originally reported campaigns are collected. Perhaps it is forthcoming?

James W. King

Univeristy of Hawaii

“CARTOONS: WHEN ARE THEY EFFECTIVE”' by James M. Nehiley, assistant professor, Institute of Food and Agricultural Science; James Stephens, associate professor, Institute of Food and Agricultural Science; and John Sutherland, assistant professor, College of Journalism, University of Florida-Gainesville (Journal of Extension, Vol. XX, March/April 1982) pages 14-21. 


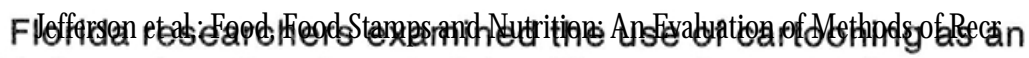
aid for educational materials. The major question was, "Would the use of an illustrated format significantly increase comprehension among audiences with limited reading abilities?" Three objectives were established in an attempt to answer this question. They sought:

(1) To determine whether limited resource audiences can have significantly higher rates of comprehension studying cartoon-style material than a similar audience studying regular extension publications

(2) To determine whether limited resource audiences might have significantly lower rates of content comprehension than an audience with a higher reading level, if both groups were exposed to the same cartoon-style material

(3) To determine whether limited resource audiences can have a significantly higher opinion of cartoon-styled publications than non-limited resource audiences.

The reseachers chose a gardening publication and treated the same material in cartoon-style. The original publication tested at 11th-grade level, while the revised cartoon version was written at Fourth- or Fifth-grade level. The Fry and Flesch readability tests were used.

The study indicated that "illustrated educational materials specifically targeted for audiences with limited learning abilities resulted in higher comprehension of the subject matter by those audiences." Those with average or above average incomes and education were positive about the illustrated format. The study assumed the college students had higher reading levels than the limited resource group. However, the study colild not determine whether material targeted for the limited resource audience could result in an increase in comprehension by other audiences.

They concluded the cartoon-style material holds great potential as a teaching source. They also stated that research is needed to answer two key questions:

- Will audiences with greater learning abilities use material developed for limited resource audiences?

- Will the attitudes of extension agents and leaders adversely affect the use of this type of material?

Some answers came in a survey of all Florida extension offices. Responses indicated most agents approved of material targeted for limited resource audiences. However, 


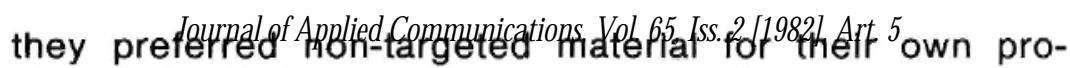
grams. The limited resource audience enthusiastically approved the material. The agents participating in the program, however, reported that most of their limited resource clients disapproved of the materials because they were "childish."

A conflict exists which indicated careful audience analysis and content analysis of material designed for target audiences. Careful examination of those two factors plus the manner of presentation are important. Florida researchers say more studies can determine the potential for targeted, illustrated materials, and the agents who use the material. Additional information is needed by extension educators "to analyze the effects of these publication strategies before targeting materials for their audiences."

Debrah H. Jefferson

University of Missouri-Columbia

\section{"Science Meets the Press," by William E. Bur- rows, in Current, June 1980, Number 223 (Reprinted from "Science Meets the Press: Bad Chemistry"' in The Sciences, April 1980.)}

"Science has defined twentieth-century America," William E. Burrows writes, adding, "For a sort of grand finale, science and technology gave us the moon."

But all is not well these days, according to Burrows, who believes science is on a collision course with the public while scientists are on a collision course of their own with journalists.

A former reporter for The New York Times and The Washington Post, Burrows is now Director of the Scientific and Environmental Reporting Program at New York University. Better yet, he's a lively, thoughtful writer on a subject that concerns ag communicators as much as journalists and educators-namely, strained relations between the scientific community, the press, and the general public.

When science meets the press, for example, "Scientists think that whatever they tell a reporter is bound to come out wrong," while reporters have scientists pegged as "unemotional, uncommunicative, unintelligible creatures." 


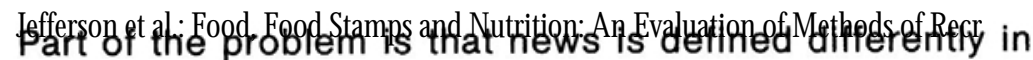
the laboratory and the newsroom. Journalism is readeroriented, Burrows points out, while pure science is selforiented. Besides, journalists are usually more interested in the what of a situation and in its effects, while scientists prefer to ponder why and look for causes.

Meanwhile readers of science news have problems of their own, Burrows thinks. He attributes their disillusionment with science and scientists to the kind of bad vibes generated by a Love Canal or a Three Mile Island crisis. Such unfortunate examples of the fallibility of science hit Americans especially hard because for years they worshipped it with a "gratitude and faith approaching the religious," as Burrows puts it.

Scientists, on the other hand, have always known they were not gods or heroes and resent having to take the blame for technological failures. They know that-more often than not-government and industry are to blame, not science.

In any case, Burrows makes his case that the press, the public, and the scientific community are not getting along as well as they should. What to do about it?

Burrows puts the ball in science's court. The scientific community ought to strive for as much public support as possible, he says, by "spreading around generous amounts of information" about science. To do this, he suggests that scientists work harder at popularizing science with the help of journalists. (He might have included ag communicators, since most of us spend the working day spreading around generous amounts of information about the ag sciences.)

Burrows thinks scientists should be helping to educate science writers instead of merely complaining about the quality of reporting. For the benefit of working journalists he suggests intensive four- or five-day courses sponsored by national and regional scientific associations in conjunction with university departments of journalism. (Most ag communicators would probably have no quarrel with that idea.)

For students-the journalists and ag communicators of the future-he proposes a center for environmental and science reporting at a major university, and tells us that NYU is trying to start such a center. Since Burrows' article appeared two years ago, I called him to find out how his plans were shaping up.

He reported that his new graduate program will begin in September to train science and environmental affairs communicators for the news media, the public affairs sector, and 
government. The program sound's intriguing and unusual, with heavy doses of science (taught by scientists) and reality (discussions of tough ethical questions).

Details are available from Burrows (Meyer Hall of Physics, New York University, NYC 10003), but I thought his assessment of the program summed it up nicely. He said the 15 students accepted for the program can expect to feel "like they're in drill camp in the marine corps. This is going to be an elite program. They've got to be very smart. I want this program to be world-class."

Dot Sparer

University of Georgia

\section{"Multimedia Instruction: High Learning, Low Cost" by Karin Kristiansson, Journal of Extension (Vol. XIX, Nov.-Dec. 1981)}

More states realize program accessibility and cost effectiveness are important aspects of delivery systems. Findings from a one-year study by Vermont and Nevada showed the following:

- A well-planned and carefully implemented mass media education program can reach thousands of people not previously aware of extension.

- A combination of multimedia instruction systems can prove highly effective and can cost less than the traditional extension one-to-one methods.

These results were from a special, intensive 10-week nutrition program funded by SEA-Extension for 1979-80. The cooperatively planned and implemented program reached 17,000 food-stamp families in rural Vermont and 7,000 urban families in Las Vegas, Nevada.

A key to success was program identification. The unwieldly project name of EFNEP Multimedia Nutrition Education Project became "Good Food-Good Times."

The project compared three teaching methods:

- System 1: direct mail, television, and telephone instruction by education assistants

- System 2: direct mail and television

- System 3: direct teaching-one-to-one or small group by education assistants 


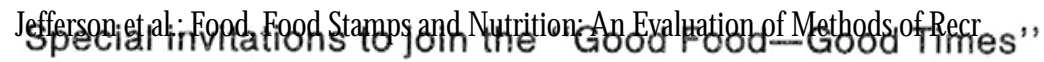
program were sent to potential participants on state foodstamp rolls. Enrollment cards were included in the easy-toread announcements. As a result of special enrollment efforts, 2,903 Vermont and 670 Nevada food-stamp families enrolled and completed a two-page pretest that included questions on nutrition, food behavior and shopping practices.

Results indicated that a combination of all three systems tailored to each participant's motivation, need and education provides a more cost-effective way to reach more lowincome families than small group or one-to-one methods. When the overall performance and program costs per participant were anlayzed, the systems ranked as follows:

- System 2: low costs and high performance,

- System 1: medium costs and high performance,

- System 3: high costs and high performance.

Telephone instruction received high marks. Neither Vermont nor Nevada had used this technique before the project. Both assistants and participants gave the technique high acceptance. The program assistants reported they could teach almost as much in a five-minute telephone conversation as in a 30-minute personal contact.

Questions the journal article did not address included air time and production costs for materials. Both these could be important factors before other states attempt duplicating broadcasts. The table from the article (cost comparison of three instructional systems) implies the study's concern was participant costs which varied because of numbers enrolled in each system. System two can reach more people for less because contact time with program assistants was eliminated. These participants received weekly direct mail mini-lessons and were encouraged to watch television programming. Naturally, larger audiences than the target group are possible with television.

Table 2. Cost comparison of the three instructional systems.

\begin{tabular}{|c|c|c|c|c|c|c|}
\hline & \multicolumn{2}{|c|}{ System 1} & \multicolumn{2}{|c|}{ System 2} & \multicolumn{2}{|c|}{ System 3} \\
\hline & $\begin{array}{l}\text { No. parti- } \\
\text { cipants }\end{array}$ & $\begin{array}{l}\text { Cost per } \\
\text { particpant }\end{array}$ & $\begin{array}{l}\text { No. part- } \\
\text { cipants }\end{array}$ & $\begin{array}{l}\text { Cost per } \\
\text { participants }\end{array}$ & $\begin{array}{l}\text { No. part- } \\
\text { cipants }\end{array}$ & $\begin{array}{l}\text { Cost per } \\
\text { participant }\end{array}$ \\
\hline Vermont & 757 & $\$ 42.25$ & 1,857 & $\$ 19.15$ & 154 & $\$ 113.37$ \\
\hline Nevada & 262 & 47.35 & 265 & 35.06 & 51 & 109.24 \\
\hline
\end{tabular}




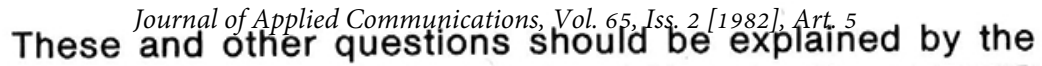
project coordinators in Vermont and Nevada. More EFNEP and other extension audiences are being reached by alternative delivery methods. Greater usage of electronic media will become apparent in the future. Their usage should be tracked.

Debrah H. Jefferson

University of Missouri-Columbia 